\title{
Anomalies in Structure, Growth Characteristics, and Nutritional Composition as Induced by 2,4-Dichlorophenoxy Acetic Acid Drift Phytotoxicity in Grapevine Leaves and Clusters
}

\author{
Bhaskar R. Bondada ${ }^{1}$ \\ Washington State University Tri-Cities, 2710 University Drive, Richland, WA 99354
}

\begin{abstract}
ADDITIONAL INDEX wORDs. fasciation, live green ovary, lobes, mesophyll, Vitis vinifera, sinus, true berry
ABSTRACT. Drift hazards and the effects of 2,4-dichlorophenoxy acetic acid (2,4-D) spray drift on woody perennials have been commonly observed since its discovery in the 1940s; however, 2,4-D-induced phytotoxicity, morphogenesis, and structural and compositional anomalies of their vegetative and reproductive structures are not well understood. Healthy and 2,4-D-injured shoots of grapevine (Vitis vinifera L.) from a commercial vineyard experiencing persistent drift were compared. The morphoanatomy of healthy and 2,4-D-injured leaves and berries were examined using light and scanning electron microscopy (SEM). Along with the microscopic examinations, stomatal conductance $\left(g_{\mathrm{S}}\right)$, leaf growth characteristics, and mineral composition were also determined. The morphoanatomy of healthy leaves resembled that of a typical angiospermic leaf. By contrast, shoots exposed to 2,4-D phytotoxicity displayed epinastic behavior and developed grotesquely malformed leaves that were thick, fan-shaped, enated, and interveinally puckered as a result of fasciation of veins. The cellular architecture, including the vascular bundles, was altered as a result of the formation of parenchymatous replacement tissues. The $g_{\mathrm{S}}$, leaf index, leaf area, and petiole dimensions were significantly reduced in the 2,4-D-injured leaves. 2,4-D-injured leaves; however, accumulated high levels of nitrogen, potassium, and iron compared with healthy leaves. The clusters (fertilized inflorescences) of the injured shoots developed epinastic curvature and predominantly bore live green ovaries (seedless unripened pseudofruit) instead of true berries (fertilized fully ripened fleshy fruit). These abnormalities are expected to severely perturb the vital functions of photosynthesis and transpiration as evidenced by low $g_{S}$ and poor fruit set leading to senescence and localized necrosis ultimately causing death of current-season shoots.
\end{abstract}

Leaves serve as the prime mediator with the environment above the soil surface and, despite their temporary nature, dominate the shoot system because they play multiple roles. For instance, in woody perennials, they protect the fruit and young plants against excess sunlight and wind damage. As an entire and integrated organ within the canopy, leaves manufacture photosynthates and export them to the fruit and woody framework. Furthermore, they provide vital clues about the physiological status of the whole plant. So, as a sole armor and a significant provider for fruit as well as the whole plant, leaves are particularly vulnerable to injury caused by biotic and abiotic forces. One of the prominent abiotic forces to which leaves and reproductive structures frequently succumb entails phytotoxicity of off-target movement of chemicals against which there are no control measures (Bondada, 2010). These chemicals primarily include vapors and spray drifts of phenoxy herbicides (Bondada et al., 2006). As many as 100 or more herbicide formulations are known to contain a phenoxy-type a.i. and among them, one of the most commonly used phenoxy products is 2,4-D, a synthetic auxinic herbicide that selectively kills broadleaved weeds (Grossmann, 2000). Because of its predilection for damaging broad-leaved plants, woody perennials in orchards and vineyards worldwide are not only kept free of 2,4-D, but also avoided in grape production except for generating embryos and plantlets from tissue culture (Rajasekaran and

Received for publication 8 Oct. 2010. Accepted for publication 6 Jan. 2011. I thank Eileen Harbertson for her help with preparing and processing some of the samples for light microscopy.

1E-mail: bbondada@wsu.edu.
Mullins, 1979). Despite preventive measures, 2,4-D ends up in vineyards through vapors and spray drifts from fields of row crops where it is typically applied during May and June. This coincides not only with a period of rapid shoot growth, but also flowering and fruit set, for instance in grapevine (Al-Khatib et al., 1993). Once drifted to these locations, leaves readily absorb and translocate the particles and volatiles of 2,4-D (Bovey, 1971). In most woody perennials (Epps, 1959; Hibbs, 1978), especially grapevines, injury had been observed both in leaves that absorbed 2,4-D and sink organs (developing leaves, meristems, etc.) (Hallam and Sargent, 1970; Weintraub, 1953). Fruit also acts as a sink drawing photosynthates from the leaves; if 2,4-D is present in leaf at that critical time, then it also can be drawn to the clusters (Weaver et al., 1958).

Drift hazards and the effects of 2,4-D spray drift on woody perennials such as apple (Pyrus malus L.), cherry (Prunus avium L.), grape (Vitis L.), and fruit trees in general have been commonly observed since its discovery in the 1940s and are well documented in the literature (Al-Khatib et al., 1993; Bhatti et al., 1995; Bondada et al., 2006; Epps, 1959; Hibbs, 1978; Sherwood et al., 1970). Despite their sensitivity to 2,4-D, not much is known about the injury. Indeed, there are several studies recorded in the literature; however, these were conducted several years after the discovery of 2,4-D in the 1940s that examined the symptoms of 2,4-D injury with anatomical details primarily in cereal crops such as nut grass [Cyperus rotundus L. (Eames, 1949)], rice [Oryza sativa L. (Kaufman, 1955)], and wheat [Triticum aestivum L. (Johanson and Muzik, 1961)] or in organs other than leaves of row crops (Eames, 1950). Thus, the available information on 2,4-D injury is ubiquitous 
but fragmentary necessitating a holistic view (i.e., seeing the big picture of 2,4-D phytotoxicity by performing an integrated analysis of cellular and growth anomalies in other plant species of different ecological origin). Grapevine is among the most important woody perennial in terms of cultivated area and economic impact (Pilati et al., 2007). Because 2,4-D spray drift is a recurring hazard to vineyards (Bhatti et al., 1996; Bondada et al., 2006; Kasimatis et al., 1968) and the fact that grapevines are supersensitive to 2,4-D (Bondada, 2010; Hale, 1968), they fit the model woody perennial species for analyzing and understanding the mechanistic basis of 2,4-D-induced morphogenesis and structural and compositional anomalies of vegetative and reproductive structures.

It is well known that herbicides can strongly influence growth and nutritional status of plants. For instance, paclobutrazol, a potent gibberellin synthesis inhibitor, significantly altered leaf nutrient content resulting in decreased levels of nitrogen, phosphorus, potassium, iron, and molybdenum and increased levels of calcium, magnesium, boron, and manganese in peach rootstock [Prunus persica (L). Batsch $\times$ Prunus davidiana Carriere] (Rieger and Scalabrelli, 1990). In Arabidopsis thaliana (L.) Henyh., the blade width, blade length, and petiole length reflect the mediolateral and proximodistal dimensions of leaves and therefore are important indices of leaf shape (Liu et al., 2010). For instance, leaf index (length to breadth ratio) has been examined to study variation in leaf morphology both within and between species (Tsukaya, 2002). Whether 2,4-D alters leaf index, fruit formation, or nutrient accumulation in perennials is not known; however, in light of its potency as an herbicide, it is postulated that 2,4-D injury will severely perturb organized growth and differentiation of tissues and organs resulting in major abnormalities in structure and growth. The objective of this study was to elucidate the 2,4-D-induced phytotoxicity, symptomatology, and the possible mechanisms involved in the ensuing structural, nutrient compositional, and growth anomalies in grapevine leaves and clusters by performing comparative analysis against healthy leaves and clusters.

\section{Materials and Methods}

Plant material. Mature grapevines of the cultivars Merlot and Malbec from commercial vineyards located in the Columbia Valley, WA (lat. 46 35'38' N, long. $119^{\circ} 09^{\prime} 08^{\prime \prime} \mathrm{W}$ ) were used for examining the symptoms, anatomy, and morphology of leaves and clusters injured by 2,4-D drift. The vineyards with north-south row orientation had vine by row spacing of $1.83 \times$ $2.74 \mathrm{~m}$ on a uniformly deep (greater than $1 \mathrm{~m}$ ) loamy fine sand. Vines were trained to two trunks and a bilateral cordon, which entailed training the vines in both directions along the cordon (an extension of the trunk) wire from the trunk. Training in viticulture parlance refers to the design and development of a grapevine framework. The shoots emerging from the cordon were positioned vertically using catch wires. Vines were spurpruned during winter [i.e., canes (mature woody and lignified stems from the previous season's shoots)] were cut back to two count nodes/buds (the readily visible buds on a dormant cane, not including the small base buds); the noncount shoots (i.e., shoots arising from base buds of the spur) were removed at the beginning of bloom that approximately equated to 20 shoots $/ \mathrm{m}$. Standard cultural practices were adopted to maintain healthy vines. These vineyards were chosen because they consistently developed 2,4-D-induced symptoms year after year by accumulating 2,4-D in the meristematic regions of the shoot that led to loss of their structural integrity perturbing the developmental process. The grapevines were monitored for 2,4-D phytotoxicity early in the season (May to June); once shoots displayed typical symptoms of 2,4-D injury (Bondada et al., 2006), they were cut using a pruner and immediately brought to the laboratory with their cut ends immersed in a flask filled with water. Healthy shoots from a nearby block unaffected by 2,4-D drift were also collected in a similar manner for comparison. The symptoms of 2,4-D injury on whole shoots and severed leaves were photographed using a digital camera (Canon USA, Lake Success, NY).

Light Microscopy. Small leaf tissue samples were cut using a razor blade; subsequently, the tissues were fixed and preserved in formalin-acetic acid-alcohol. The fixed tissues were dehydrated using the tertiary butyl alcohol series, infiltrated and embedded in paraffin, sectioned at $\approx 10 \mu \mathrm{m}$ with a microtome (MT 990; Boeckeler Instruments, Tucson, AZ), affixed to glass slides $(8 \times 3 \mathrm{~cm})$, and stained with the Toluidine blue $(1 \%)$ and Johansen's safranin [1\% (w/v) dissolved in 50\% ethanol] and fast green $[0.2 \%(\mathrm{w} / \mathrm{v})$ dissolved in $95 \%$ ethanol] protocol (Ruzin, 1999). The staining procedure involved rehydration in descending strengths of alcohol, staining with safranin, dehydration in ascending strengths of alcohol, and counterstaining with fast green. When staining was complete, a drop of Permount mounting medium (Fisher Scientific, Fair Lawn, NJ) was used to affix coverslips to the slides. Slides were placed under a compound microscope (Axioskop 2 plus; Carl Zeiss, Thornwood, NY) attached with a digital camera (DXM 1200C; Nikon Instruments, Melville, NY), which was used for capturing digital images.

BERRY ANATOMy. To determine the effect of 2,4-D on the internal structure including vasculature (especially the xylem vasculature), both true berries and live green ovaries (LGOs) were examined after they had been passively infused with an apoplastic dye [basic fuchsin $0.1 \%$ aqueous (Talboy, 1955)]. For passive dye infusion, the technique used by Bondada et al. (2005) was used. Briefly, the berries were excised from the rachis, and the pedicel of an intact berry was trimmed and immediately dipped in a small reservoir of the dye solution. Infusion through the cut pedicel was allowed to occur for 6 to $7 \mathrm{~h}$ under laboratory conditions. Berries were then either crosssectioned at the proximal (pedicel) and distal (stylar) end or were sectioned longitudinally through the center to examine the pericarp and seed structure and the pattern and extent of xylem staining with a stereomicroscope (Stemi 2000-C; Carl Zeiss) attached with digital camera (DXM 1200C), which was used for capturing digital images.

SCANNING ELECTRON Microscopy. For SEM, the method described by Achor et al. (1991) was adopted. Briefly, tissue samples from leaves were cut using a razor blade, fixed in 3\% glutaraldehyde overnight, washed with $0.1 \mathrm{M}$ potassium phosphate buffer at $\mathrm{pH} 7.2$, and post-fixed in $2 \%$ osmium tetroxide overnight. The leaf samples were then dehydrated in an ascending series of ethanols ending in 100\% ethanol. The tissue samples were subsequently critical point-dried, coated with gold, and viewed with a SEM (S-570; Hitachi Scientific Instruments, Mountain View, CA) using an accelerated voltage of $15 \mathrm{kV}$. Before using the SEM, the scope magnification was calibrated by photographing a gold grid and compared with a standard. The spot size was set toward the maximum diameter 
and minimum beam intensity with a standard working distance of $8 \mathrm{~mm}$.

LeAf CLEARING. Leaves were cleared using 5\% NaOH and chloral hydrate (Sigma-Aldrich, St. Louis, MO) solutions. First leaves were soaked in $5 \% \mathrm{NaOH}$ solution until the chlorophyll was removed and leaves became fairly clear. Thereafter, leaves were treated with chloral hydrate to ensure complete removal of chlorophyll and stained with safranin. When staining was complete, a drop of Permount mounting medium was used to affix coverslips to the slides. Slides were placed under a compound microscope (Axioskop 2 plus) attached with a digital camera (DXM 1200C), which was used for capturing digital images.

Measurement of Leaf dimensions and Stomatal CONDUCTANCE. Measurements of leaf dimensions were made on individual healthy and 2,4-D-injured leaves. Leaf area was determined with a leaf area meter (LI-3000; LI-COR, Lincoln, $\mathrm{NE}$ ). Leaf length, from the tip to the joining point of the petiole and the lamina, was measured to the nearest $1 \mathrm{~mm}$ with a ruler. Leaf width, across the widest part of the lamina to assess lateral expansion of the leaf, and petiole length were also measured to the nearest $1 \mathrm{~mm}$ with a ruler, whereas petiole diameter was measured using a vernier caliper. The ratio of leaf length to leaf width (length:width), an index of leaf shape, was calculated for individual leaves. Stomatal conductance was measured using a leaf porometer (SC-1; Decagon Devices, Pullman, WA).

Nutrient AnAlysis. Dry weights of healthy and 2,4-Dinjured leaves from three replications were measured by placing tissues in an oven at $70{ }^{\circ} \mathrm{C}$ for 1 week. Dried leaf tissue was ground to 20-mesh size and then determined elemental composition of leaves by a commercial laboratory using inductively coupled plasma spectroscopy (Soltanpour et al., 1996).

Tests of significance between healthy and 2,4-D-injured leaves were analyzed by using Student's $t$ test $(P<0.05)$. Three replications of 18 leaves were used for each treatment (healthy and 2,4-D injury). The data were analyzed using the SPSS (Version 11; SPSS, Chicago, IL) statistical package.

\section{Results}

Terminology for characters in healthy leaves follows those used for dicot leaves. Because both cultivars Malbec and Merlot displayed similar injury symptoms and structural modifications, micrographs of injuries and the ensuing effects from both cultivars were used to compose figures. The healthy shoots exhibited an upright growth habit in which the caulescent (having a distinct upright stem) stem consisted of nodes, internodes, leaves, tendrils, and clusters (fertilized inflorescence) positioned at the basal third to fifth nodes (Fig. 1A). The healthy leaves possessed subregions along their longitudinal axes represented by leaf base, petiole, and a cuneiform, applanate (flattened), and chartaceous (papery) lamina (Fig. 1B). The lamina developed with round sinuses that separated the lamina into five lobes. A lobate base occurred at the proximal end of the leaf wherein the lobe was defined by a central sinus known as a petiolar sinus confining the petiole and by inferior and superior sinuses on their distal sides such that the nadirs of these sinuses were within the base of the leaf (Fig. 1B). The five sinuses corresponded to five lobes, one distal apical lobe and two pairs of lateral lobes; one pair occurred in the medial transverse plane and

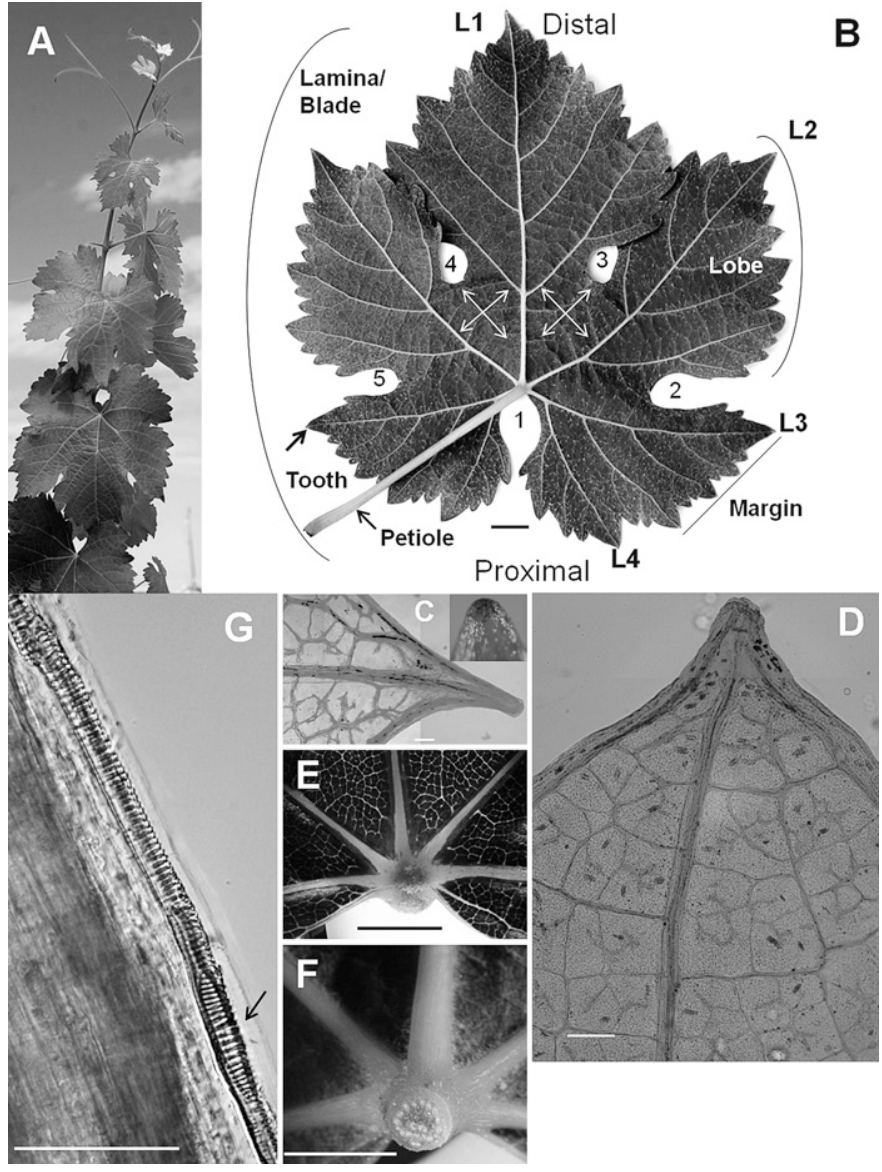

Fig. 1. Photographs of (A) control treatment entailing healthy 'Merlot' grapevine shoot without any 2,4-dichlorophenoxy acetic acid injury showing upright growth habit; (B) the abaxial side of a 'Merlot' grapevine leaf from A showing the reticulate venation pattern, proximal and distal poles, which define the proximodistal polarity (plane), and the midvein and margin, which define the mediolateral polarity. The proximal region of the leaf forms a petiole, and the lamina or leaf blade develops more distally. The blade is traversed by five major veins arising from a petiole; these are called midvein (L1), superior lateral veins (L2 and $\mathrm{L}^{\prime} 2$ ), and inferior lateral veins (L3 and $\mathrm{L}^{\prime} 3$ ) corresponding to five sinuses that separate the lamina into five lobes; L4 and $\mathrm{L}^{\prime} 4$ represent petiolar veins diverging closely from the insertion point (double cross arrows indicate lateral expansion); (C) light micrograph of the tip of the apical lobe of a grapevine leaf from $\mathbf{A}$, inset-hydathode; (D) light micrograph of the tip of one of the lateral lobes of a grapevine leaf from $\mathbf{A} ;(\mathbf{E})$ stereomicrograph of the adaxial (ventral) surface of the insertion point where the lamina joins the petiole in a leaf from $\mathbf{A}$; $(\mathbf{F})$ stereomicrograph of the abaxial (dorsal) surface showing the ribs of the five major veins originating from the insertion point of the same grapevine leaf as shown in $\mathbf{E} ;(\mathbf{G})$ xylem vessel elements with annular thickening and a scalariform perforation plate in a healthy grapevine leaf vein from A. Scale bars: $10 \mathrm{~mm}(\mathbf{B}), 200 \mu \mathrm{m}(\mathbf{C}-\mathbf{D})$, $500 \mu \mathrm{m}(\mathbf{E}-\mathbf{F}), 50 \mu \mathrm{m}(\mathbf{G})$.

the other in the proximal end of the leaf. Each lobe had dentate margin with an acuminate tip in the apical lobe (Fig. 1C) and an acute tip in the lateral lobes (Fig. 1D) all ending in hydathodes (Fig. 1C, inset). Because vascular patterning is intimately associated with leaf development, five major veins originating from the petiole and numerous anastomosing ones of various sizes crossed through each lobe of the lamina (Figs. 1B and 1E). As per Galet (1979), these are called midvein (L1), superior lateral veins (L2 and L'2), and inferior lateral veins (L3 and L'3). Furthermore, the inferior lateral veins included two petiolar veins (L4 and L'4) diverging closely from the insertion point. The 
petiolar sinus was located at the insertion point in between the proximal lobes of L4 and L' 4 (petiolar veins). The two inferior lateral sinuses were positioned between L3 (lobes of the inferior vein) and L2 (lobes of the superior vein). The two superior lateral sinuses were in between L2 (lobe of the superior lateral vein) and L1 (apical lobe of the midvein). Among these, the midvein was the most robust (Fig. 1B). All five major veins had ribs of a round outline that projected from the base of the abaxial surface, thus visible macroscopically, whereas the smaller veins lacked ribs (Figs. 1B and 1F). The xylem of the veins consisted of vessel elements with spiral thickening and scalariform perforation plate (Fig. 1G). The height (thickness) of ridges was maximal in the proximal end of the lamina and decreased toward the distal end of the margins. The major veins ramified palmately confining anastomoses (veins that are primarily cylindrical bundles of vascular tissues of many sizes) and areoles, which ended the veins and together they constructed a reticulate venation pattern in the intercostal (between veins) regions (Fig. 1B-E). These inconspicuous veins could be easily differentiated from the major veins of all ranks by examining externally as they formed abaxial ridges, whereas the small veins were embedded in the mesophyll, usually beneath the palisade cells; i.e., in the uppermost layer of the spongy parenchyma (Figs. 1B and 1E). The shiny borders of the areoles represented bundle sheath extensions (BSEs), which extended horizontally along a given vein segment and united at vein junctions with other extensions to form contiguous compartments of the areoles (Fig. 1E).

The lamina of healthy leaves exhibited the typical threedimensional leaf form specified along the proximodistal (baseto-tip), dorsiventral (adaxial-to-abaxial), and mediolateral (middle-to-margin) axes (Figs. 1B and 2A). The lamina was flattened perpendicular to their dorsiventral (bifacial) axis in which the mesophyll tissues consisting of elongated palisade parenchyma cells developed ventrally toward the adaxial surface and the porous spongy parenchyma cells dorsally toward the abaxial surface (Fig. 2A). A single layer of epidermis covered the leaf on both surfaces (Fig. 2A). The spongy mesophyll had four to five layers of spherical to polygonal to irregularly lobed cells surrounded by an extensive system of air spaces that formed a continuum with the outside air through substomatal cavities and stomatal pores. Furthermore, the mesophyll tissue was permeated and spread by five mechanically stabilizing major veins (Fig. 1B). In a transverse section of one of the major veins, the central pith was enclosed by a ring of six collateral vascular bundles (four small and two large bundles) embedded in the parenchymatic rib tissues, each constructed of phloem external to the xylem (Fig. 2B-C). Between the two large bundles, the largest one was abaxially positioned in close proximity to the abaxial surface and the relatively smaller bundle was adaxially positioned in the rib tissues. Each large bundle was flanked by two small vascular bundles, collectively giving the impression of two arcs of vascular bundles (Fig. 2B-C). The vascular bundles were separated from the mesophyll of the lamina by parenchyma cells (Fig. 2B). The ground tissue of the rib consisted of several layers of spherical parenchyma cells of varying sizes (Fig. 2B).

A transverse section through the small vein with lamina in healthy leaf revealed one vascular bundle with adaxially positioned primary xylem and abaxially positioned primary phloem surrounded by parenchymatous bundle sheath cells (Fig. 2D). The BSEs, which are panels of cells similar to those in the bundle sheath, were vertically oriented between the
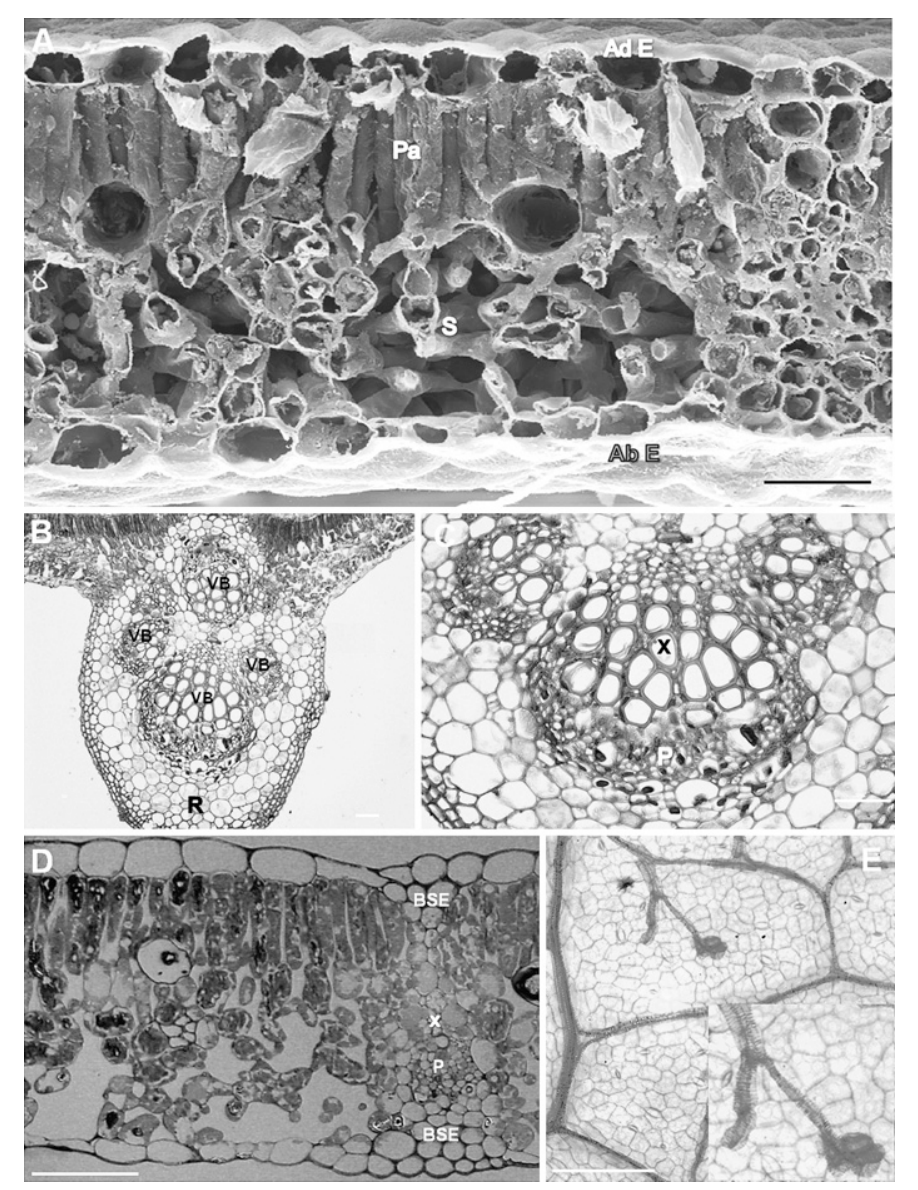

Fig. 2. Scanning electron micrograph of a cross-section of (A) a control healthy 'Merlot' grapevine leaf without any 2,4-dichlorophenoxy acetic acid (2,4-D) injury showing adaxial epidermis, abaxial epidermis, palisade parenchyma cells, and spongy mesophyll cells; (B) light micrograph of a control healthy 'Malbec' grapevine leaf cross-section through a major vein without any 2,4-D injury showing six vascular bundles and rib tissues; (C) enlargement of the abaxial vascular bundles of $\mathbf{B}$ showing xylem and phloem poles; (D) light micrograph of a control healthy 'Merlot' grapevine leaf cross-section through a small vein without any 2,4-D injury showing xylem, phloem, and bundle sheath extension extending toward both epidermises; (E) light micrograph of a control healthy 'Merlot' grapevine leaf clearing without any 2,4-D injury showing areoles with numerous blind vein endings. Scale bar: (A) $34 \mu \mathrm{m}$, (B-E) $50 \mu \mathrm{m}$. Ad E = adaxial epidermis; $\mathrm{Ab} \mathrm{E}=$ abaxial epidermis; $\mathrm{BSE}=$ bundle sheath extension; $\mathrm{Pa}=$ palisade parenchyma cells; $\mathrm{R}=$ rib tissue; $\mathrm{S}=$ spongy mesophyll cells; $\mathrm{X}=$ xylem; $\mathrm{P}=$ phloem; $\mathrm{VB}=$ vascular bundle.

vascular bundle and epidermises and formed a vertical partition through the lamina (Fig. 2D). The BSE cells were two to five cells wide and extended into opposite directions toward respective epidermal layers (Fig. 2D). Leaf clearings were obtained to observe a minor vein pattern. The areoles were large with free vein endings, which consisted of multiple (normally two) spiral tracheids blindly ending in the areole (Fig. 2E).

The vines with healthy leaves yielded grape ('Malbec') clusters that possessed one or two shoulders (upper lateral branches) and were conical to cylindrical in shape (Fig. 3A). It consisted of a stalk or peduncle (hypoclade) that attached the cluster to a certain node position in the stem, and a rachis, to which the berries were attached with a short pedicel, the ultimate branching of the rachis (Fig. 3A). The berries were $\approx 12 \mathrm{~mm}$ in diameter and spherical in shape (Fig. 3B). Because the growth and development of unripened (green) berries after 

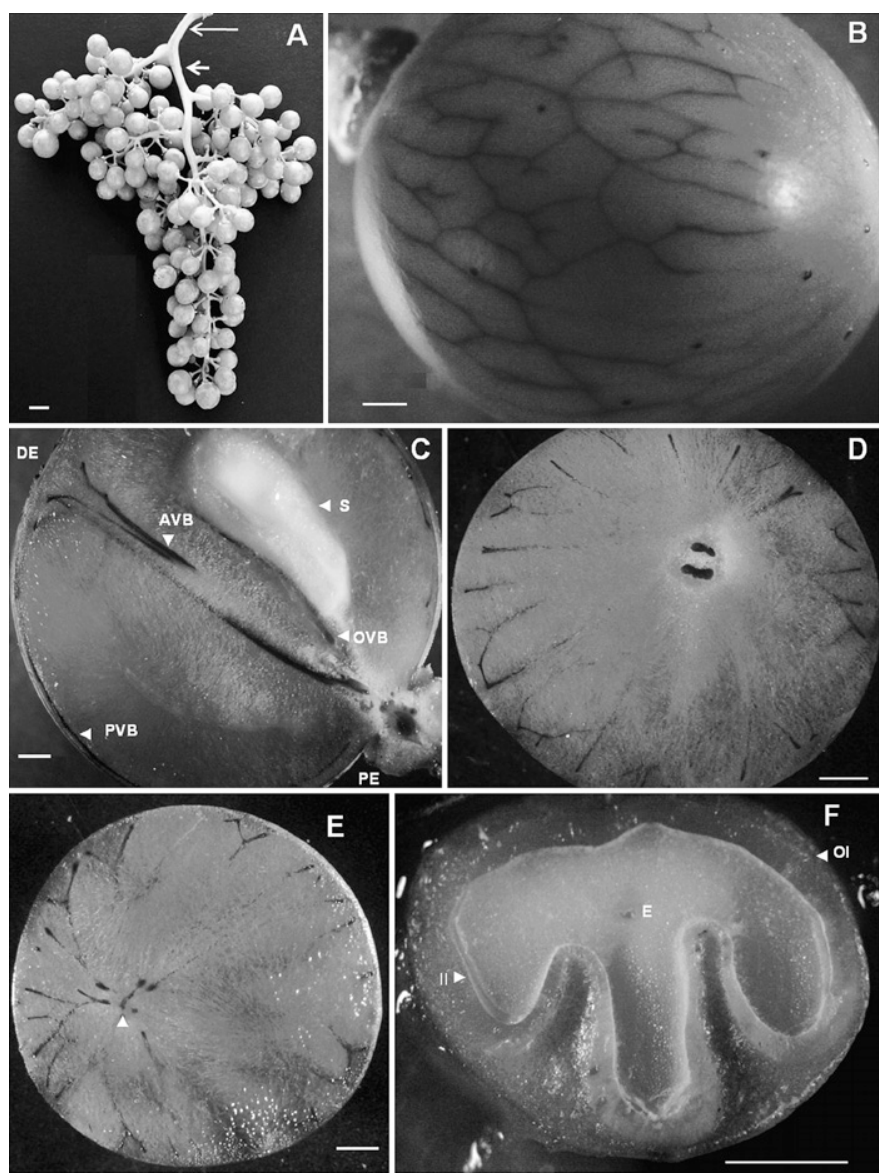

Fig. 3. Photograph of (A) control treatment entailing a healthy 'Malbec' grapevine cluster without any 2,4-dichlorophenoxy acetic acid injury; (B) a spherical berry from A showing the surface view of the peripheral vascular network; (C) longitudinal section of a healthy true berry (i.e., B) showing the three vascular bundles (axial, ovular, and peripheral) and a seed; (D) transverse sectional view of proximal (pedicel end) ramification of the peripheral vascular network in B; (E) transverse sectional view of union (arrowhead) of the peripheral vascular network with the axial vascular bundle at the stylar (distal) end in $\mathbf{B}$; (F) central transversal section of a healthy seed from $\mathbf{B}$ showing outer and inner integuments and the endosperm. In all vascular bundles, the red staining indicates the presence of xylem. Scale bar: (A) $10 \mathrm{~mm},(\mathbf{B}-\mathbf{E})$ $1 \mathrm{~mm} . \mathrm{AVB}=$ axial vascular bundle; $\mathrm{E}=$ endosperm; $\mathrm{II}=$ inner integument; $\mathrm{OVB}=$ ovular vascular bundle; $\mathrm{PVB}=$ peripheral vascular bundle; $\mathrm{OU}=$ outer integument; $\mathrm{PE}=$ proximal (pedicel) end; $\mathrm{S}=$ seed; $\mathrm{DE}=$ distal (stylar) end.

pollination and fertilization predominantly occur through the contribution made by the xylem vasculature (Bondada et al., 2005; Coombe, 1987; Keller et al., 2006), it was important to examine the integrity of this pathway. The distribution pattern of the xylem-specific dye indicated that the healthy berries were fed by means of vascular bundles in the pedicel that entered the berry as a group consisting of three components (Fig. 3C). One of the components, the axial vascular bundle, extended into the distal pole of the berry (Fig. 3C), the second component, the highly ramified peripheral or dorsal vascular bundle branching out from the axial vascular bundle at the proximal end (Fig. 3C3D) and then again uniting with the axial vascular bundle at its distal end, was located just beneath the exocarp (Figs. 3B, 3C and $3 \mathrm{E})$. The third component entailed the ovular vascular bundles that served the seeds (ovules) (Fig. 3C). The berries developed with two locules each containing two seeds in the ovary; one of the seeds is shown in Figure 3C. Two locules and four seeds are the norm for healthy grape berries. The seeds exhibited well-developed outer and inner integuments and an endosperm (Fig. 3F). The berries of healthy clusters were referred to as true berries because they had well-developed pericrap and seeds.

In terms of leaf growth characteristics and functionality, the healthy leaves exhibited the highest values for all parameters, and these values were significantly greater than the values observed in 2,4-D-injured leaves (Table 1). For instance, the leaves were fully expanded with large leaf area, long petioles of increased diameter, and a high leaf index and $g_{\mathrm{S}}$ (Table 1). By contrast, the healthy leaves accumulated significantly lower levels of nitrogen, potassium, and iron than the 2,4-D-injured leaves, whereas there was no significant difference between healthy and injured leaves for the remaining macro- and micronutrients (Fig. 4A-B).

Unlike the healthy shoots, the 2,4-D-injured shoots exhibited epinastic behavior by growing in a zig-zag manner, yet the shoots grew with distinct nodes, internodes, leaves, tendrils, and clusters as observed in the healthy shoots (Fig. 5A). The shoots with distorted architecture developed grotesque and malformed leaves (both young and old) that were coriaceous (leathery) and resembled a fan. Furthermore, injured leaves were reduced in size, and the amount of reduction was in direct proportion to the severity of injury. Most veins were fasciated into wide bands of unpigmented tissues (Fig. 5B-C). On the adaxial surface, the lamina swelled forming several small linear protuberances between fasciated veins transforming the flat lamina into a rumpled surface (Fig. 5B). The petiolar sinus disappeared, whereas the lateral sinuses became angular and the base resembled that of a cuneate (wedge-shaped with acute angles) leaf base (Fig. 5B). The fasciation of veins was truly remarkable and distinct from the abaxial surface (Fig. 5D). Several versions of fasciation were observed. For instance, either the midlateral veins fasciated with midvein (Fig. 5D) or the lower lateral veins fasciated with midlateral veins leaving the midvein alone (Fig. 5E). The protuberances on the adaxial surface corresponded to deep grooves on the abaxial surface (Fig. 5E). The leaf margins displayed sharp projections (enations), which pointed in every direction (Fig. 5F). Each projection represented a morphed double-convex tooth of the dentate margin. The interior of sinuses along the leaf margin widened forcing the teeth singly, paired, or grouped to rise

Table 1. Leaf growth characteristics and stomatal conductance $\left(g_{\mathrm{S}}\right)$ of 'Merlot' grapevine as influenced by 2,4-dichlorophenoxy acetic acid $(2,4-\mathrm{D}){ }^{\mathrm{z}}$

\begin{tabular}{lcc}
\hline $\begin{array}{l}\text { Growth } \\
\text { characteristics }\end{array}$ & $\begin{array}{c}\text { Healthy leaves } \\
(\text { mean } \pm \mathrm{SE})\end{array}$ & $\begin{array}{c}\text { 2,4-D-injured } \\
\text { leaves }(\text { mean } \pm \mathrm{SE})\end{array}$ \\
\hline Leaf area $\left(\mathrm{cm}^{2}\right)$ & $115.6 \pm 12.9 \mathrm{a}^{\mathrm{x}}$ & $67.81 \pm 12.4 \mathrm{~b}$ \\
Leaf index & $0.94 \pm 0.03 \mathrm{a}$ & $0.74 \pm 0.06 \mathrm{~b}$ \\
Petiole length $(\mathrm{cm})$ & $3.47 \pm 0.60 \mathrm{a}$ & $1.47 \pm 0.27 \mathrm{~b}$ \\
Petiole diameter $(\mathrm{mm})$ & $2.52 \pm 0.23 \mathrm{a}$ & $1.28 \pm 0.03 \mathrm{~b}$ \\
$g_{\mathrm{S}}\left(\mathrm{mmol} \cdot \mathrm{m}^{-2} \cdot \mathrm{s}^{-1}\right)$ & $109 \pm 11.3 \mathrm{a}$ & $47.3 \pm 6.12 \mathrm{~b}$ \\
\hline
\end{tabular}

${ }^{\mathrm{z}}$ Treatments included healthy leaves and leaves injured by 2,4-D.

yThe ratio of leaf length to leaf width (length: width), an index of leaf shape.

${ }^{x}$ Means followed by the same letter within a row are not significantly different by Student's $t$ test at $P<0.05$. 

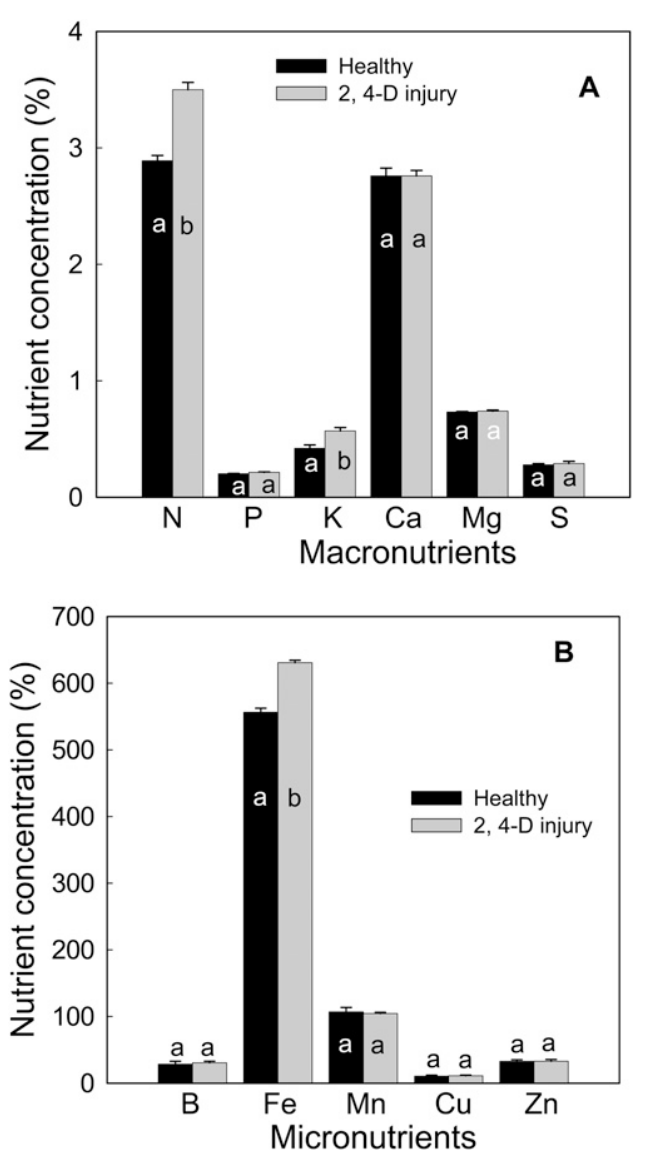

Fig. 4. (A) Macronutrient and micronutrient concentrations (\%) of control treatment entailing healthy 'Merlot' grapevine leaves without any 2,4dichlorophenoxy acetic acid (2,4-D) injury and 2,4-D-injured 'Merlot' grapevine leaves. (B) Micronutrient concentration of control healthy leaves (dark bars) and of 2,4-D-injured leaves (gray bars). Within a nutrient, bars (mean $\pm \mathrm{SE}$ ) sharing a common letter are not significantly different according to a Student's $t$ test at $P<0.05$.

above the contour of the margin (Fig. 5F-G). In more severe cases in which the lobes were clumped together, the projections occurred as one group (Fig. 5H). When all sinuses disappeared, the leaves became funnel-shaped (Fig. 5I).

The degree of leaf modification in 2,4-D-injured leaves depended on the fasciation of veins; the greater the fasciation, the greater the distortion and veinyness of the lamina (Fig. 6). Small veins without prominent ribs formed a closely tangled mass where the vascular bundles remained close together often becoming severely appressed (Fig. 6A). The normal interveinal tissues were absent and much of the blade was supplanted by parenchymatous tissues that had no intercellular spaces. Parenchyma cells farthest from the vascular bundles were largest and those adjacent to the vascular bundles were smallest (Fig. 6A). Furthermore, the parenchymatous tissue in the fasciated veins was continuous from the adaxial to the abaxial epidermis. On the abaxial surface, a few subepidermal layers and several on the adaxial surfaces were collenchymatously thickened. In the fasciated veins with ribs, the vascular bundles were discrete; however, the parenchymatous tissues surrounding the vascular bundles were continuous through much of the width of the leaf (Fig. 6B-C). The tissues between fasciated veins became irregular with massing of small veins and islet tissues in an uneven triangular wedge of meshwork wherein the underdeveloped

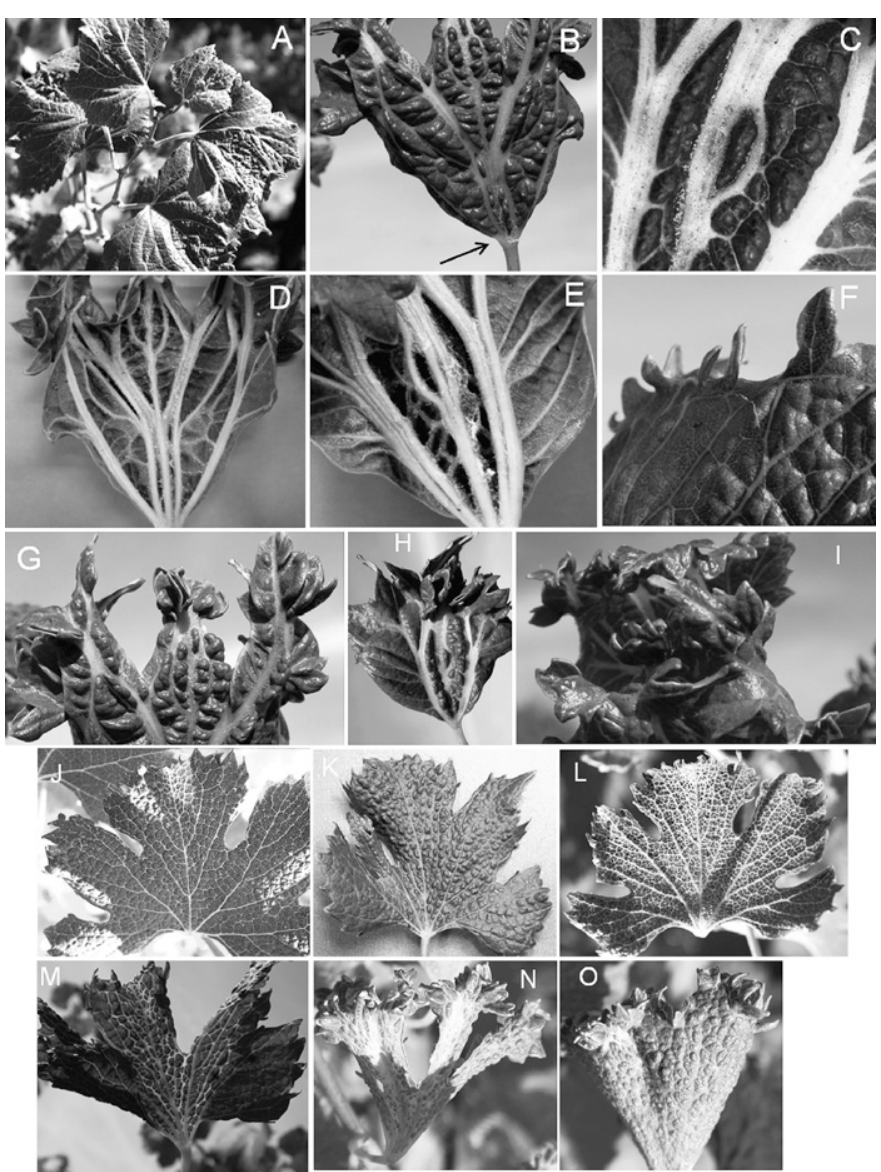

Fig. 5. Photograph of (A) a 'Merlot' grapevine shoot injured by 2,4dichlorophenoxy acetic acid showing a zig-zag growth pattern; (B) adaxial surface of malformed and puckered grapevine leaf from A showing fasciated veins and interveinal rugose bands of lamina (arrow indicates loss of petiolar sinus); (C) fasciated veins of B lacking chlorophyll; (D) abaxial surface of $\mathbf{B}$ showing fasciated medial and midlateral major veins; $(\mathbf{E})$ abaxial surface of a grapevine leaf from $\mathbf{A}$ showing fasciated lower and midlateral major veins; F-H from A showing enations (morphed tooth) of a different degree; (F) single teeth; (G) paired teeth; $(\mathbf{H})$ cluster of teeth; (I) extremely malformed grapevine leaves (funnel shape); (J-O) photographs of 2,4-dichlorophenoxy acetic acid injury ratings as per the severity of injury ratings $(0-5)$ developed by Ogg et al. (1991), which corresponded to as follows: $\mathbf{J}=1, \mathbf{K}=2, \mathbf{L}-\mathbf{M}=3$, $\mathbf{N}=4, \mathbf{O}=5$.

mesophyll tissues were disoriented with the development of parenchymatous tissues on the abaxial surface (Fig. 6B). Like in the small veins, a few abaxial subepidermal layers and several on the adaxial surfaces were collenchymatously thickened (Fig. 6B). Additional parenchymatous tissues appeared above and below the veins accentuating the ribs on the dorsal (abaxial/lower) surface and also building up ventral (adaxial/upper) ridges (Fig. $6 \mathrm{~B}-\mathrm{C}$ ). Most of the vein eyelets (areoles) between the fasciated veins had not formed (Fig. 6B); if formed, they then were constricted by the bulging fasciated veins (Fig. 6C). The rugose bands of lamina between the fasciated veins in the transverse section displayed internal tissues being organized in a cordate architecture with a medial-lateral symmetry (Fig. 6D). In this symmetry, the mesophyll tissues were interrupted by several fasciated small veins with additional continuous large parenchymatous tissues mostly on the abaxial surface. In the fasciated veins, the mesophyll tissue was restricted to islets immediately below the epidermis (Fig. 6D). The strikingly conspicuous feature 


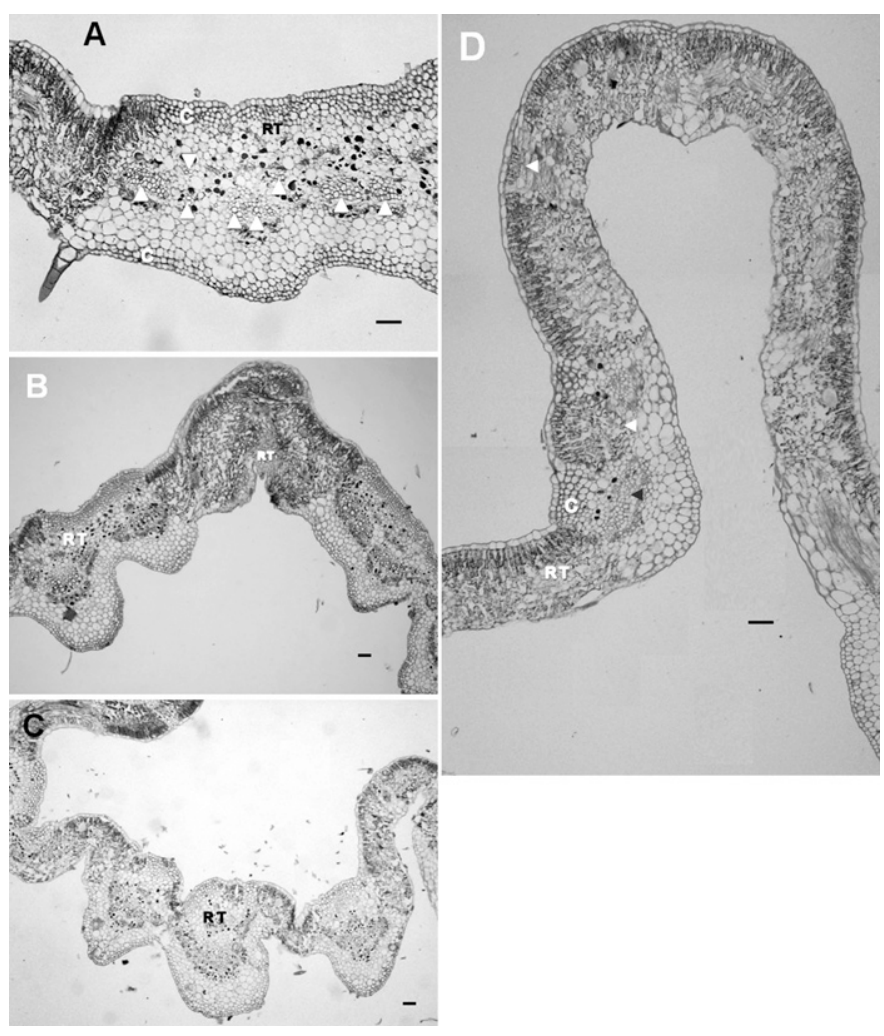

Fig. 6. Transverse light micrographs of 'Malbec' grapevine leaf injured by 2,4dichlorophenoxy acetic acid showing fasciation of veins; the greater the fasciation, the greater the distortion and veinyness of the lamina. (A) Small fasciated veins lacking ribs confining closely appressed vascular bundles; (B) fasciated veins with ribs from opposing sides confining discrete vascular bundles and continuous parenchymatous tissues formed a dome-shaped mass of small veins and islet tissues; (C) several fasciated veins with discrete vascular bundles and additional parenchymatous tissues above and below the veins accentuating the ribs on the dorsal surface and building up ridges on the ventral surface; (D) a rugose band of lamina between the fasciated veins in a transverse section displaying internal tissue organization in a cordate architecture with a medial-lateral symmetry and the mesophyll tissues interrupted by several fasciated small veins. Scale bars: $50 \mu \mathrm{m}$ (A-D). BSE = bundle sheath extension; $\mathrm{C}=$ collenchyma cells; $\mathrm{RT}=$ replacement tissue; blue arrowheads = vascular bundles; white arrow heads = subepidermal islet of mesophyll tissues.

of the rugose bands of lamina was the occurrence of a small vein with BSE at its median that dichotomized the mediallateral symmetry. In all veins, the abaxial BSE cells were distinctly larger than adaxial BSE cells (Fig. 6D). In the opposing cordate arms at the central horizontal plane, the mesophyll with intrusive veins appeared to be normal with elongated palisade parenchyma and porous spongy mesophyll cells.

In mesophyll tissues where vein fasciation did not occur, the complexes of vascular bundles, bundle sheaths, and BSE extending from upper to lower epidermal layers were greatly enlarged in 2,4-D-injured leaves in both horizontal and vertical directions in cross-sectional view (Fig. 7A). Furthermore, the air space in the mesophyll was greatly reduced (Fig. 7A). On both surfaces, the vascular bundle was capped by ridges of several layers of collenchymatously thickened BSE (Fig. 7A). The BSE cells were eight to 13 cells wide and six to seven cells in height. Dense populations of small areoles with no vein endings occurred in the rumpled surface (Fig. 7B). If vein endings existed, then it occurred as multiple (more than two) reticulate
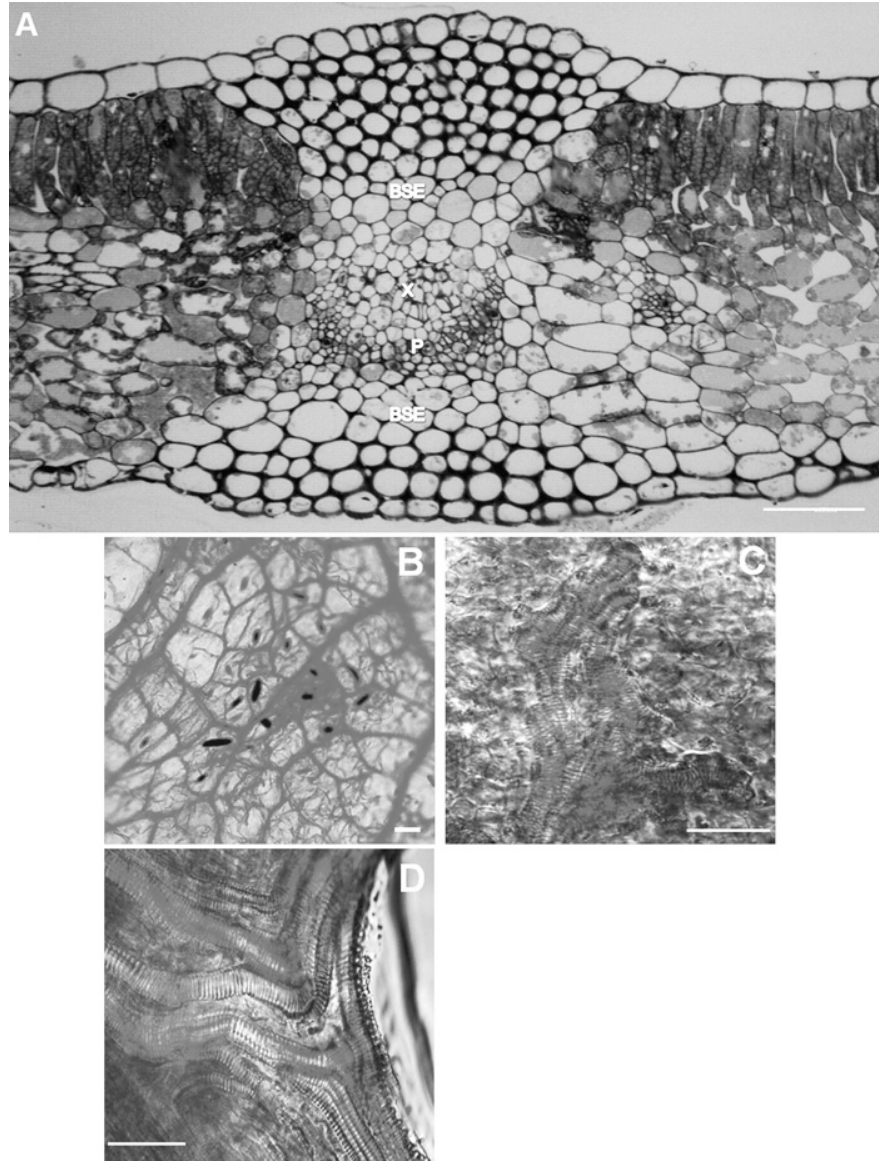

Fig. 7. Light micrographs of 'Merlot' grapevine leaf injured by 2,4-dichlorophenoxy acetic acid. Transversal section through a small vein of injured grapevine leaf (A) showing a vascular bundle with adaxially positioned primary xylem and abaxially positioned primary phloem surrounded by parenchymatous bundle sheath cells. Several wide layers of collenchymatously thickened bundle sheath extensions were vertically oriented between the vascular bundle and epidermises forming a vertical partition through the lamina; (B) dense populations of areoles in injured grapevine leaves with no vein endings; (C) a fasciated forked vein tip of injured grapevine leaf; (D) distorted vessel elements with annular thickening in veins of injured grapevine leaf. Scale bars: $50 \mu \mathrm{m}$ (A), $50 \mu \mathrm{m}$ (B), $25 \mu \mathrm{m}$ (C), $50 \mu \mathrm{m}(\mathbf{D})$.

tracheids that were irregular and fasciated (Fig. 7C). The fasciated veins showed distorted vessel elements with spiral thickening (Fig. 7D).

Like in the healthy clusters, the 2,4-D-injured clusters consisted of a stalk or peduncle (hypoclade) and a rachis (Fig. 8A). However, two odd phenomena were observed in 2,4-D-injured clusters; first, epinastic curvatures of clusters (rachis) and second, formation of LGOs (Fig. 8A). The LGOs were $\approx 4 \mathrm{~mm}$ in diameter and spherical in shape (Fig. 8B-C) and just like the healthy berries, the LGOs were fed by means of axial, ovular, and peripheral vascular bundles (Fig. 8D). The ovary had two locules; one of the locules was empty, whereas the other locule contained two malformed ovules (Fig. 8D-E). Consequently, the striking feature of LGO was poor seed development with no pericarp (Fig. 8D-E). The interior of the seeds appeared to be atrophied; furthermore, there was neither the development of an embryo nor an endosperm (Fig. 8E).

With respect to leaf growth characteristics and functionality, leaf area, petiole dimensions, and leaf index, all were significantly 


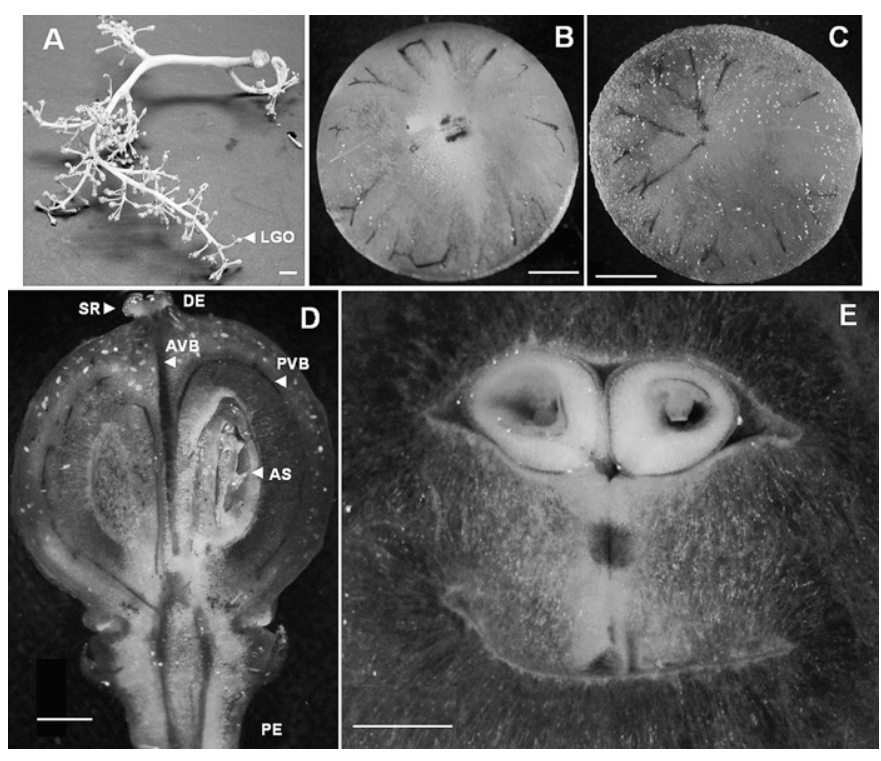

Fig. 8. Epinastic characteristics of 'Malbec' grapevine clusters injured by 2,4-dichlorophenoxy acetic acid. (A) A severely distorted grapevine cluster with the rachis bearing solely live green ovaries (LGOs). Transversal stereomicrographs of LGO showing (B) proximal (pedicel end) ramification of peripheral vascular network and (C) distal (stylar end) union of the peripheral vascular network at the stylar end. Longitudinal section of (D) a LGO showing axial and peripheral vascular bundles and atrophied seed; (E) transversal section of LGO with two locules; one of them had atrophied seeds. In all vascular bundles, the red staining indicates the presence of xylem. Scale bar: $10 \mathrm{~mm}(\mathbf{A}), 1000 \mu \mathrm{m}(\mathbf{B}-\mathbf{C}), 500 \mu \mathrm{m}$ (D-E). AVB = axial vascular bundle; $\mathrm{AS}=$ atrophied seed; $\mathrm{DE}=$ distal (stylar) end; $\mathrm{PVB}=$ peripheral vascular bundle; $\mathrm{PE}=$ proximal (pedicel) end; $\mathrm{SR}=$ stigma remnants

reduced in the 2,4-D-injured leaves (Table 1). Also, the $g_{\mathrm{S}}$ was significantly lower in the 2,4-D-injured leaves. However, the nutritional composition was in favor of 2,4-D-injured leaves in that it had significantly higher concentrations of nitrogen, potassium, and iron (Fig. 4F-G). There was no significant difference in the remaining macro- and micronutrients between the healthy and 2,4-D-injured leaves.

\section{Discussion}

While the 2,4-D-injured leaves were undergoing morphoanatomical modifications (Figs. 5 and6), the shoots free of 2,4-D grew upright (Fig. 1A) with healthy membranous leaves (Fig. 1B) of polarities along the three axes (Fig. 2). Leaves exhibiting such polarities generally arise from cell cycle activities in the marginal meristem (Donnelly et al., 1999), intercalary meristem (Pratt, 1974; Tsukaya, 2000), and from the progression of cell cycle arrest front, which is the boundary where the switch from proliferation to expansion occurs within leaf primordia (Nath et al., 2003). Among these three axes, the adaxial-abaxial polarity is of primary importance because it is required for the flattened dorsiventral structure with an adaxial and abaxial epidermis, which results from rapid cell division along the margins during its development from leaf primordia (Tsukaya, 2000). The rationale for any angiospermic leaf (including the cultivars of this study) to acquire such characteristics is to maximize interception of light by collecting incident light on the upper surface and diffusing it (both scattered and reflected) on the lower surface (Niinemets et al., 2004). Other morphological features that leaves develop to increase efficiency of light interception and elevate rates of photosynthesis include lobes with dentate margins (Baker-Brosh and Peet, 1997; Niklas, 1989), but no data exist that bear on these issues in grapevine (e.g., 'Merlot' in this study). However, what is certain about dentate lobation in grapevine cultivars is that it arises from the differential activity of the leaf margins starting early in ontogenesis (Pratt, 1974).

Obviously, the petiole in petiolated leaves serves to attach the lamina to the node of the stem. With respect to grapevines, the petiole (Fig. 1B) performs additional functions. For instance, it functions in minimizing self-shading of leaves, enables the lamina to track the sun, and minimizes the damaging effects of wind on the thin paper-like structure of the lamina by twisting and partly rotating in the wind. In effect, it is a continuation of the stem and distributes the vascular bundles called leaf traces from the stem (at nodes) to the lamina (Lacroix and Posluszny, 1991; Stevenson et al., 2004) so as to transport inorganic and organic molecules between the stem and the blade (Esau, 1977). Once in the leaf, they are called veins such as the major veins observed in 'Merlot' and 'Malbec', wherein the vascular bundles are embedded in a ridge of parenchymatous tissues with a relatively small amount of chlorophyll and supporting tissues in the form of collenchyma that project from the abaxial surface of the leaf forming a rib. These vascular bundles are known to develop continuous, open vessels originating from the base of the petiole (Thorne et al., 2006) and ending before the leaf margins in the form of both vessels (proximal end) and as tracheids (distal ends) (Chatelet et al., 2006). The subsequent branching from major veins follows progressively decreasing rib tissues indicating that the greatest mechanical stress occurs along the longitudinal axis of a leaf (Givinish, 1987), which explains the intense robustness of the midmajor vein. Endowed with increased rib tissues, the major veins have greater individuality than any of the laterals but become less closely associated spatially with the mesophyll and increasingly embedded in the rib tissues, which is a common condition in dicotyledonous leaves (Fisher, 1985). Although conspicuous, the major veins constitute only a small fraction $(\approx 5 \%)$ of the total vein length (Wylie, 1939).

With regard to vein network, the healthy grapevine leaves (Fig. 1B-D) similar to any dicot leaf developed a hierarchical and reticular venation gaining several advantages over leaves lacking such a branching pattern. For instance, netted (reticulate) venation has been known to provide redundancy of transport pathways that minimizes the deleterious effect of insects and other sources of damage (i.e., cavitation) on transport pathways while at the same time provides a physical barrier limiting the spread of such damage (Salleo et al., 1997). Developmental mechanisms that specify the reticulate venation pattern are not known but are generally believed to be driven by the canalization of auxin flux (Berleth et al., 2007). In that reticulate venation pattern, the major vein network serves as the major supply lines for the smaller veins, which in turn act as the service channels making up the distributive system for the mesophyll (Chatelet et al., 2006; Thorne et al., 2006). Thus, altogether, the vein network functions as the main irrigation system of the lamina irrigating the mesophyll tissues during photosynthesis (Zwieniecki et al., 2002). This division of labor based on the hierarchical organization of a ramifying transport system is a common principle in both technical and biological systems (Vogel, 1994). 
Just like the major veins, the epidermis and the cuticle also act as stabilizing (stiffening) agents (Niklas and Paolillo, 1997). However, because the epidermal cells constitute the outermost layers and thus are in direct contact with the outside environment, they primarily serve to protect the interior tissues against ultraviolet light, water loss, herbivory, and pathogen attack (Kutschera, 2008). They accomplish such roles by synthesizing and accumulating a wide range of secondary metabolites, including flavonoids, wax precursors, terpenes, and alkaloids (Bondada et al., 1994, 1996; Dudareva et al., 2005; Kutchan, 2005). Other roles may include driving and restricting shoot growth (Savaldi-Goldstein et al., 2007; Scheres, 2007). Although the epidermal layers serve to protect against abiotic forces, they were defenseless against vapors and spray drifts of 2,4-D. Indeed, the epidermal cells along with its cuticular covering act as entry points for the absorption of phenoxy herbicides, including 2,4-D (Bovey, 1971) as evidenced by 2,4-D injury in this study.

Like in any angiospermic leaf, the epidermal layers of healthy leaves (Figs. 2A and 2D) confine the mesophyll tissues. The palisade parenchyma cells of the mesophyll tissues in grapevine species and cultivars (Pratt, 1974), and perhaps in most dicot leaves, are typically elongated; however, the shape and number of spongy mesophyll cells vary depending on Vitis species. For instance, $V$. aestivalis possessed cubic or prismatic cells with small air spaces and $V$. rupestris exhibited up to six to seven layers of cells (Manzoni, 1954). This structural differentiation of mesophyll tissues into palisade parenchyma and spongy mesophyll cells common to most angiospermic dicot leaves relates to the differences in physiological function between the two cell types within the leaf (Vogelmann et al., 1996). The columnar cells of palisade mesophyll have a shape suited to maximal stacking of chloroplasts for light harvesting, whereas the lobed cells of the spongy mesophyll create air spaces between the cells for rapid diffusion of gases during photosynthetic carbon fixation (Martin et al., 2001). Thus, by partially separating the physiological functions through differences in anatomy, the grapevine leaves including other C3 (refers to $\mathrm{C} 3$ photosynthesis) mesophytes optimize the interception and use of available sunlight, maximize $\mathrm{CO}_{2}$ diffusion into the leaf tissue, and minimize transpirational water loss. These morphoanatomical features of healthy leaves (Fig. 2) account for the development of clusters of true berries (Fig. 3). True berries are those berries, which develop seeds with embryo and endosperm embedded in a fleshy pericarp (Harris et al., 1968; Longbottom et al., 2008). Such berries with their seeds grow to full maturity and ripeness when fed with the three vascular networks facilitated by xylem and phloem (Bondada et al., 2005; Chatelet et al., 2008; Keller et al., 2006) as observed in the healthy clusters (Fig. 3A).

Unlike the healthy shoots (Fig. 1A), the 2,4-D-injured shoots exhibited epinastic behavior (Fig. 5A). Much of this might have resulted from epinastic effects that arise from the common property of all auxins to enhance production of ethylene, which is notorious for causing epinasty (Grossmann, 2000). The change in shoot architecture was discernible (Fig. 5A); however, the most conspicuous feature of 2,4-D-injured shoot was the altered physiognomy (size and shape) and architecture (venation pattern, marginal configuration, etc.) of the leaves (Fig. 5B-O), which displayed corrugated lamina on the adaxial surface (Fig. 5B), pointed margins (Fig. 5F), and bleached veins (Fig. 5C). Although not quite the same, similar symptoms had been reported in bean [Phaseolus vulgaris L. (Eames, 1951)], spinach [Raphanus bipinnatus L. (Kendrick and Middleton, 1954)], and cotton (Gossypium hirsutum L.) and soybean (Glycine $\max$ L.) (Sciumbato et al., 2004). Because imbalance in polarity, cell division, and auxin response are characterized by altered shoot architecture and leaf shape such as curly, crinkly, twisted, rolled, or shrunken leaves (Liu et al., 2010), these anomalous morphological structures of 2,4-D-injured leaves were strong indicators of a perturbed leaf developmental process manifested as fasciation of veins and a lack of interveinal expansion. These two phenomena were the most dramatic effects of 2,4-D injury at the morphological level. Fasciation is an abnormal condition that results in flattening of normal cylindrical structures (White, 1948). Although fasciation has been reported to be one of the widespread developmental abnormalities in higher plants resulting from mutations, various infections, traumas or amputation of the apical meristem, deficiency of microelements, etc. (Sinjushin and Gostimsky, 2006), in grapevines, it has been mostly observed in response to 2,4-D injury (Bondada, 2010). However, a mild form of fasciation was observed in response to the abscission agent, morphactin (Weaver and Pool, 1971). Regardless of the source of fasciation, ultimately it results in disturbed metabolism involving mobilization of energy that must be used and must go into growth resulting in an extravagant, abnormal, and unpredictable tissue production as had been observed in the 2,4-D-injured leaves of this study (Fig. 5D-E), generally to the detriment of the plant (Sinjushin and Gostimsky, 2006). When fasciation did not occur, the complexes of vascular bundles, bundle sheaths, and BSE extending from upper to lower epidermal layers were still greatly enlarged in the 2,4-D-injured leaves (Fig. 7A). This phenomenon was predominantly the result of the growth ensuing from an increase in number of cells of bundle sheaths and their extensions. The 2,4-D analog 2, 4, 5-T (2, 4, 5-trichlorophenoxyacetic acid) acted in a similar manner in apricot (Prunus armeniaca L.) leaves (Bradley et al., 1968).

To account for a lack of interveinal expansion, one has to consider how grapevine leaves expand. Like in other dicotyledonous species, grapevine leaves expand by growth in their marginal meristem and by intercalary meristematic activity in its six layers (plate meristem) (Pratt, 1974). Given the fact that 2,4-D is translocated through phloem and primarily accumulates in the meristematic regions (Teixeira et al., 2007), one can conjecture that the reduction in leaf size was brought about by the failure of the derivatives of the meristem to develop normally resulting in reduced lateral expansion of the interveinal parts of the blade. This was evidenced by the rugose condition (ruffled surface) of the lamina (Fig. 5B) and the fasciated veins (Fig. 5D-E) brought about by proliferation of cells manifested as extra parenchymatous tissues. Formation of these extra cell layers in response to 2,4-D injury have been identified as "replacement tissue" (Dickison, 2000). One important aspect of the replacement tissues was that they remained closely packed with no intercellular spaces (Fig. 6). Thus, failure of these cells to separate reduced the lateral expansion of the lamina and consequently the leaf blade did not become thinner. Furthermore, the replacement tissues conferred on the 2,4-Dinjured leaves a ruffled surface with the formation of rugose bands of lamina (Fig. 6B-D). How the replacement tissues induced such architecture is not within the domain of this study; however, in view of its unique feature in response to 2,4-D injury, it is well worth analyzing the rugose bands of lamina in the 
context of how curvatures occur in whole leaves. The rugose bands can be considered as an example of local curvature of lamina between the fasciated veins as opposed to global curvature as the whole leaves curve [e.g., PEAPOD mutant of A. thaliana (White, 2006)]. Because both scenarios have curvatures in common, it is reasonable to expect that comparable mechanics are involved in these two curvature types. Accordingly, because enhanced growth mediated by cell proliferation generates compressive stress (Boudaoud, 2010), which is accountable for leaf curvatures in the cincinnata mutant of snapdragon [Antirrhinum majus L. (Nath et al., 2003)] and the peapod mutant of $A$. thaliana (White, 2006), it is highly plausible that the ruffling effect in 2,4-D-injured leaves arose by similar mechanical interactions of cells at the local tissue level.

The extreme events of dense population of areoles with no vein endings (Fig. 7B) or fasciated endings (Fig. 7C) and distorted xylem vessels of veins (Fig. 7D) are related to a lack of lamina expansion because the vein pattern is formed during the intercalary extension growth of the leaf blade usually in a basipetal sequence (Esau, 1965). These two phenomena, fasciation of veins (Fig. 5D-E) and a rumpled adaxial surface (Fig. 5B), caused a severe reduction in the photosynthetic leaf area. Because leaves are the seat of vital functions of photosynthesis and transpiration (Bondada et al., 1994), the loss in photosynthetic leaf area has many implications for vine health and fruit production. For example, 2,4-D injury delayed ripening of grapes or reduced the ability to ripen a crop causing a reduction in yield as much as $85 \%$ in severe cases (Al-Khatib et al., 1993; Ogg et al., 1991) and a significant reduction in cotton yield (Marple et al., 2008).

With reference to injury to clusters, first the curvature of rachis (Fig. 8A) was inevitably the result of the epinastyinducing action of 2,4-D through abnormally high rates of ethylene synthesis, a well-known action of 2,4-D widely documented in the literature (e.g., Grossmann, 2000). Second, instead of true berries, LGOs (Fig. 8B-E), also known as shot berries (Longbottom et al., 2008), were distributed throughout the cluster. May (2000) describes shot berries as those that form after pollination but without fertilization (i.e., they form through stimulative parthenocarpy). Because the formation of LGOs occurs through stimulative parthenocarpy after pollination but without fertilization, the formation of LGOs in 2,4-Dinjured clusters indicated that 2,4-D had a direct effect on fertilization most likely by causing injury to pollen grains leading to poor fruit set. The studies by Weaver et al. (1961) corroborate this hypothesis in that they showed that when 'Tokay' grape flowering clusters were dipped in 2,4-D solutions, the number of seedless berries (LGOs) increased as a result of an injurious effect of 2,4-D on the germination of pollen grains. Hence, in the absence of fertilization, the LGOs produced no viable seeds (Fig. 8D-E); instead, they just had ovules with atrophied interiors surrounded by integumentary tissues (Fig. 8D-E). A similar phenomenon was observed in cereals, wherein 2,4-D reduced production of viable seeds indicating a lack of embryo and endosperm development (Rinella et al., 2010). In general, grape clusters develop LGOs whenever flowering (fertilization) coincides with adverse weather conditions (May, 2000). In such cases, the septum was found to be wounded and lignified impeding the progression of pollen tubes to ovules (Cholet et al., 2002) as opposed to poor germination of pollen grains in 2,4-D-injured flowering clusters (Weaver et al., 1961). These studies indicated that regardless of the mechanisms involved in preventing fertilization, the ultimate result is the formation of LGOs. Although the LGOs failed to develop viable seeds, their xylem vasculature appeared to be intact (Fig. 8B-D) indicating a hydraulic connection with the mother vine and their formation was primarily the result of failed fertilization. By contrast, the modified vein patterning in leaves with altered xylem morphology (Fig. 7B-D) may have consequences for delivery of water into leaves and translocation of photosynthates to other regions of the vines. Because LGOs do not develop color or flavor and do not accumulate sugar (Longbottom et al., 2008), they basically reduce yield by causing poor fruit set. Poor fruit set also occurs when assimilates are available in short supply during pollination and fertilization (Coombe, 1987). Hence, an indirect effect of 2,4-D on fertilization would be that 2,4-D made less assimilates available during pollination and fertilization by reducing the photosynthetic activity of 2,4-D-injured leaves as evidenced by their low $g_{S}$.

The histological phenomena of 2,4-D-injured leaves were examined in terms of leaf index (ratio of leaf length to leaf width) (Table 1), which defines leaf growth in terms of polar expansion and shape and is a function of physiological conditions and environmental factors (Tsukaya, 2002). The leaf index was significantly lower in the 2,4-D-injured leaves (Table 1), evidence of a modified internal cellular architecture attributable to changes in polar control of cell proliferation and cell expansion. This difference in leaf index between the injured and healthy leaves manifested as variations in the size and shape with healthy leaves being larger and cuneiform compared with small and fan-shaped 2,4-D-injured leaves. Altogether, it led to a severe reduction in leaf area (Table 1), not a desirable characteristic for any plant because it is directly related to light interception, transpiration, and photosynthesis and is considered to be the most important single determinant of plant productivity (Linder, 1985).

Because the organized growth and differentiation of tissues and organs of higher plants is the result of complex interactions between the hormones and available nutrients (Aberg and Eliasson, 1978), the nutrient levels in the healthy and 2,4-Dinjured leaves were analyzed. 2,4-D injury increased nitrogen (N) levels (Fig. 4A) indicating that $\mathrm{N}$ was mobilized to areas where the abnormal growth was concentrated. This was because plants treated with 2,4-D showed a large increase in nitrate content as well as an increase in levels of proteins and amino acids (Aberg and Eliasson, 1978). The potassium levels were also higher in 2,4-D-injured leaves (Fig. 4A), similar to what was observed in bean plants treated with 2,4-D (Cooke, 1957). The increase in potassium (K) in injured leaves made sense because $\mathrm{K}$ is known to play a protective role against detrimental effects ensuing from any abiotic stress (Kafkafi, 1990). For example, exposure to high levels of 2,4-D will stress any plant and when plants are stressed, they suffer from oxidative damage catalyzed by reactive oxygen species, which are produced during the photosynthetic electron transport and activation of membrane-bound NAD(P)H oxidases (Cakmak, 2005). Given that 2,4-D damages chloroplasts by accumulating in the chloroplast (Hallam and Sargent, 1970), the high level of $\mathrm{K}$ in 2,4-D-injured leaves is perhaps an adaptive mechanism to prevent oxidative damage and promote cellular function. The increased level of iron (Fe) is (Fig. 4B) tied to high levels of $\mathrm{N}$ stemming from high nitrate whose enzymatic reduction and 
assimilation requires the presence of $\mathrm{Fe}$ as a catalyst (JeanFrancois et al., 2007).

In conclusion, the current work illustrated major disparities between the healthy and 2,4-D-injured leaves signifying that the grapevines are extremely sensitive to 2,4-D phytotoxicity. This was evidenced by the fact that the mosaics of healthy structural, nutritional, and growth characteristics were grossly modified in 2,4-D-injured leaves. These modifications included epinastic shoot growth bearing thick, fan-shaped, and enated leaves with a rumpled surface as a result of fasciation of veins and uneven and disorganized growth of various cell layers within the lamina induced by formation of replacement tissues. The leaf index, leaf area, and petiole dimensions were significantly reduced in the 2,4-D-injured leaves. By contrast, 2,4-Dinjured leaves accumulated high levels of $\mathrm{N}, \mathrm{K}$, and $\mathrm{Fe}$ compared with healthy leaves. The clusters on the injured shoots exhibited epinastic curvatures that predominantly bore LGOs instead of true berries. These anomalies ultimately affected photosynthetic function of leaves evidenced by poor fruit set and low $g_{\mathrm{S}}$.

\section{Literature Cited}

Aberg, B. and L. Eliasson. 1978. The herbicidal effects of phenoxy compounds. Ecol. Bull. 27:86-100.

Achor, D.S., L.G. Albrigo, and C.W. McCoy. 1991. Developmental anatomy of lesions on 'Sunburst' mandarin leaves initiated by citrus rust mite feeding. J. Amer. Soc. Hort. Sci. 116:663-668.

Al-Khatib, K., R. Parker, and P. Fuerst. 1993. Wine grape (Vitis vinifera L.) response to simulated herbicide drift. Weed Technol. 7:97-102.

Baker-Brosh, K.F. and R.K. Peet. 1997. The ecological significance of lobed and toothed leaves in temperate forest trees. Ecology 78:1250 1255.

Berleth, T., E. Scarpella, and P. Prusinkiewicz. 2007. Towards the systems biology of auxin-transport-mediated patterning. Trends Plant Sci. 12:151-159.

Bhatti, M.A., K. Al-Khatib, and R. Parker. 1996. Wine grape (Vitis vinifera $\mathrm{L}$.) response to repeated exposure of selected sulfonylurea herbicides and 2,4-D. Weed Technol. 10:951-956.

Bhatti, M.A., A.S. Felsot, K. Al-Khatib, S. Kadir, and R. Parker. 1995. Effects of simulated chlorsulfuron drift on fruit yield and quality of sweet cherries (Prunus avium L.). Environ. Toxicol. Chem. 14:537544.

Bondada, B.R. 2010. Micromorpho-anatomical examination of 2,4-D phytotoxicity in grapevine (Vitis vinifera L.) leaves. J. Plant Growth Regulat. doi: 10.1007/s00344-010-9183-7.

Bondada, B.R., V. Hebert, and M. Keller. 2006. Morphology, anatomy, and ultrastructure of grapevine (Vitis vinifera L.) leaves injured by 2,4-D. Bot. Soc. Amer. Annu. Mtg., Chico, CA. 26 July to 2 Aug. p. 241 (Abstr.).

Bondada, B.R., M.A. Matthews, and K.A. Shackel. 2005. Functional xylem in the post-veraison grape berry. J. Expt. Bot. 56:29492957.

Bondada, B.R., D.M. Oosterhuis, J.B. Murphy, and K.S. Kim. 1996. Effect of water stress on the epicuticular wax composition and ultrastructure of cotton leaf, bract, and boll. Environ. Exp. Bot. 36: 61-69.

Bondada, B.R., D.M. Oosterhuis, S.D. Wullschleger, S.D. Kim, and W.H. Harris. 1994. Anatomical considerations related to photosynthesis in cotton leaves, bracts, and the capsule wall. J. Expt. Bot. 45: 111-118.

Boudaoud, A. 2010. An introduction to the mechanics of morphogenesis for plant biologists. Trends Plant Sci. 15:353-360.

Bovey, R.W. 1971. Hormone-like herbicides in weed control. Econ. Bot. 25:385-400.
Bradley, M.V., J.C. Crane, and N. Marei. 1968. Some histological aspects of 2, 4, 5-trichlorophenoxyaceticacid applied to mature apricot leaves. Bot. Gaz. 129:231-238.

Cakmak, I. 2005. The role of potassium in alleviating detrimental effects of abiotic stresses in plants. J. Plant Nutr. Soil Sci. 168:521-530.

Chatelet, D.S., M.A. Matthews, and T.L. Rost. 2006. Xylem structure and connectivity in grapevine (Vitis vinifera) shoots provides a passive mechanism for the spread of bacteria in grape plants. Ann. Bot. (Lond.) 98:483-494.

Chatelet, D.S., T.L. Rost, M.A. Matthews, and K.A. Shackel. 2008. The peripheral xylem of grapevine (Vitis vinifera) berries. 2. Anatomy and development. J. Expt. Bot. 59:1997-2007.

Cholet, C., L. Mondolot, and C. Andary. 2002. New histochemical observations of shot grapevine berries. Aust. J. Grape Wine Res. 8:126-131.

Cooke, A.R. 1957. Influence of 2,4-D on the uptake of minerals from the soil. Weeds 5:25-28.

Coombe, B. 1987. Distribution of solutes within the developing grape berry in relation to its morphology. Amer. J. Viticult. Enol. 38:120127.

Dickison, W.C. 2000. Integrative plant anatomy. Academic Press, San Diego, CA.

Donnelly, P.M., D. Bonetta, H. Tsukaya, R.E. Dengler, and N.G. Dengler. 1999. Cell cycling and cell enlargement in developing leaves of Arabidopsis. Dev. Biol. 215:407-419.

Dudareva, N., S. Andersson, I. Orlova, N. Gatto, M. Reichelt, D. Rhodes, W. Boland, and J. Gershenzon. 2005. The nonmevalonate pathway supports both monoterpene and sesquiterpene formation in snapdragon flowers. Proc. Natl. Acad. Sci. USA 102:933-938.

Eames, A.J. 1949. Comparative effect of spray treatments with growth-regulating substances on the nut grass, Cyperus rotundus L. and anatomical modifications following treatment with butyl 2,4dichlorophenoxy acetate. Amer. J. Bot. 36:571-584.

Eames, A.J. 1950. Destruction of phloem in young bean plants after treatment with 2,4-D. Amer. J. Bot. 37:840-847.

Eames, A.J. 1951. Leaf ontogeny and treatments with 2,4-D. Amer. J. Bot. 38:777-780.

Epps, E.A., Jr. 1959. Regulating the use of 2,4-D in the southern states. Weeds 7:108-110.

Esau, K. 1965. Vascular differentiation in plants. Holt Rinehart Winston, New York, NY.

Esau, K. 1977. Anatomy of seed plants. 2nd Ed. Wiley, New York, NY.

Fisher, D.G. 1985. Morphology and anatomy of the leaf of Coleus blumei (Lamiaceae). Amer. J. Bot. 72:392-406.

Galet, P. 1979. A practical ampelography-Grapevine identification. Comstock Publishing, London, UK.

Givinish, T.J. 1987. Comparative studies of leaf from: Assessing the relative roles of selective pressures and phylogenetic constraints. New Phytol. 106:131-160.

Grossmann, K. 2000. Mode of action of auxin herbicides: A new ending to a long, drawn out story. Trends Plant Sci. 5:506-508.

Hale, C.R. 1968. Growth and senescence of grape berry. Aust. J. Agr. Res. 19:939-945.

Hallam, N.D. and J.A. Sargent. 1970. The localization of 2,4-D in leaf tissues. Planta 94:291-295.

Harris, J.M., P.E. Kriedmann, and J.V. Possingham. 1968. Anatomical aspects of grape berry development. Vitis 7:106-119.

Hibbs, R. 1978. Recognition of weed-killer injury to trees. J. Arboriculture 4:189-191.

Jean-Francois, B., C. Curie, and F. Gaymard. 2007. Iron utilization and metabolism in plants. Curr. Opin. Plant Biol. 10:276-282.

Johanson, G.J. and T.J. Muzik. 1961. Some effects of 2,4-D on wheat yield and root growth. Bot. Gaz. 122:188-194.

Kafkafi, U. 1990. Impact of potassium in relieving plants from climatic and soil-induced stresses. 317-327. In: Johnston, A.E. (ed.). Food security in the WANA region, the essential need for balanced fertilization. Intl. Potash Inst., Basel, Switzerland. 
Kasimatis, A.N., J. Weaver, and R.M. Pool. 1968. Effects of 2,4-D and 2,4-DB on the vegetative development of 'Tokay' grapevines. Amer. J. Viticult. Enol. 19:194-204.

Kaufman, P.B. 1955. Histological responses of the rice plant (Oryza sativa) to 2,4-D. Amer. J. Bot. 42:649-659.

Keller, M., J.P. Smith, and B.R. Bondada. 2006. Ripening grape berries remain hydraulically connected to the shoot. J. Expt. Bot. 57: 2577-2587.

Kendrick, J.B., Jr. and J.T. Middleton. 1954. Funnel-leaf of spinach induced by 2,4-D. Bull. Torrey Bot. Club 2:137-140.

Kutchan, T.M. 2005. A role for intra- and intercellular translocation in natural product biosynthesis. Curr. Opin. Plant Biol. 8:292-300.

Kutschera, U. 2008. The growing outer epidermal wall: Design and physiological role of a composite structure. Ann. Bot. (Lond.) 101: 615-621.

Lacroix, C.R. and U. Posluszny. 1991. A morphometric analysis of leaf development in Vitis riparia, and grape cultivars Concord and Vivant. Can. J. Bot. 69:400-406.

Linder, S. 1985. Potential and actual production in Australian forest stands, p. 11-35. In: J.J. Landsberg and W. Parson (eds.). Research for forest management. Commonwealth Scientific and Industrial Research Organization, Melbourne, Australia.

Liu, Z., L. Jia, Y. Mao, and Y. He. 2010. Classification and quantification of leaf curvature. J. Expt. Bot. 61:2757-2767.

Longbottom, M.L., P.R. Dry, and M. Sedgley. 2008. A review of the processes and terminology used to describe grape flowering, berry development, fruit set and fruit set disordersAustral. N.Z. Grape Grower Winemakers Annu. Tech. Issue 6-14.

Manzoni, L. 1954. La foglia della vite. Rivista di Viticoltura e di Enologia 6:171-178.

Marple, M.E., K. Al-Khatib, and D.E. Peterson. 2008. Cotton injury and yield as affected by simulated drift of 2,4-D and dicamba. Weed Technol. 22:609-614.

Martin, C., K. Bhatt, and K. Baumann. 2001. Shaping in plant cell. Curr. Opin. Plant Biol. 4:540-549.

May, P. 2000. From bud to berry, with special reference to inflorescence and bunch morphology in Vitis vinifera L. Aust. J. Grape Wine Res. 6:82-98.

Nath, U., B.C.W. Crawford, R. Carpenter, and E. Coen. 2003. Genetic control of surface curvature. Science 299:1404-1407.

Niinemets, U.J., D. Tenhunen, and W. Beyschlag. 2004. Spatial and age dependent modifications of photosynthetic capacity in four Mediterranean oaks species. Funct. Plant Biol. 31:1179-1193.

Niklas, K.J. 1989. The effect of leaf-lobing on the interception of direct solar radiation. Oecologia 80:59-64.

Niklas, K.J. and D.J. Paolillo, Jr. 1997. The role of the epidermis as a stiffening agent in Tulipa (Liliaceae) stems. Amer. J. Bot. 84:734744.

Ogg A.G., Jr., A.M. Ahmedullah, and G.M. Wright. 1991. Influence of repeated application of 2,4-D on yield and juice of Concord grapes (Vitis labruscana). Weed Sci. 39:284-295.

Pilati, S., M. Perazzolli, A. Malossini, A. Cestaro, L. Demattè, P. Fontana, A.D. Ri, R. Viola, R. Velasco, and C. Moser. 2007. Genomewide transcriptional analysis of grapevine berry ripening reveals a set of genes similarly modulated during three seasons and the occurrence of an oxidative burst at veraison. BMC Genomics 8:1-22.

Pratt, C. 1974. Vegetative anatomy of cultivated grapes-A review. Amer. J. Enol. Viticult. 25:131-150.

Rajasekaran, K. and M.G. Mullins. 1979. Embryos and plantlets from cultured anthers of hybrid grapevines. J. Expt. Bot. 30:399-407.

Rieger, M. and G. Scalabrelli. 1990. Paclobutrazol, root growth, hydraulic conductivity, and nutrient uptake of Nemaguard peach. HortScience 25:95-98.

Rinella, M.J., M.R. Haferkamp, R.A. Masters, J.M. Muscha, S.E. Bellows, and L.T. Vermeire. 2010. Growth regulator herbicides prevent invasive annual grass seed production. Invasive Plant Sci. Mgt. 3:12-16.

Ruzin, S.E. 1999. Plant microtechnique and microscopy. Oxford University Press, New York, NY.

Salleo, S., A. Nardini, and M.L. Gullo. 1997. Is sclerophylly of Mediterranean evergreens an adaptation to drought? New Phytol. 135:603-612.

Savaldi-Goldstein, S., C. Peto, and J. Chory. 2007. The epidermis both drives and restricts plant shoot growth. Nature 446:199-202.

Scheres, B. 2007. The force from without. Nature 446:151-152.

Sciumbato, A.S., J.M. Chandler, S.A. Senseman, R.W. Bovey, and K.L. Smith. 2004. Determining exposure to auxin-like herbicides: I. Quantifying injury to cotton and soybean. Weed Technol. 18:1125-1134. Sherwood, C.H., J.L. Weigle, and E.L. Denisen. 1970. 2,4-D as an air pollutant: Effects on growth of representative horticultural plants. HortScience 5:211-213.

Sinjushin, A.A. and S.A. Gostimsky. 2006. Fasciation in pea: Basic principles of morphogenesis. Russ. J. Dev. Biol. 37:375-381.

Soltanpour, P.N., G.W. Johnson, S.M. Workman, J.B. Jones, Jr., and R.O. Miller. 1996. Inductively coupled plasma emission spectrometry and inductively coupled plasma-mass spectrometry, p. 91-139. In: D.L. Sparks (ed.). Methods of soil analysis. Part 3. Soil Sci. Soc. Amer., Madison, WI.

Stevenson, J.F., M.A. Matthews, L.C. Greve, J.M. Labavitch, and T.L. Rost. 2004. Grapevine susceptibility to Pierce's disease. II. Progression of anatomical symptoms. Amer. J. Enol. Viticult. 55:238-245.

Talboy, P.W. 1955. Detection of vascular tissues available for water transport in the hop by colorless derivatives of basic dyes. Nature 175:510.

Teixeira, M.C., P. Duque, and I. Sa-Correia. 2007. Environmnetal genomics: Mechanistic insights into toxicity of and resistance to the herbicide 2,4-D. Trends Biotechnol. 25:363-370.

Thorne, E.T., B.M. Young, G.M. Young, J.F. Stevenson, J.M. Labavitch, and M.A. Matthews. 2006. The structure of xylem vessels in grapevine and a possible passive mechanism for the systemic spread of bacterial disease. Amer. J. Bot. 93:497-504.

Tsukaya, H. 2000. The role of meristematic activities in the formation of leaf blades. J. Plant Res. 113:119-126.

Tsukaya, H. 2002. The leaf index: Heteroblasty, natural variation, and the genetic control of polar processes of leaf expansion. Plant Cell Physiol. 43:372-378.

Vogel, S. 1994. Life in moving fluids: The physical biology of flow. Princeton Univ. Press, Princeton, NJ.

Vogelmann, T.C., J.N. Nishio, and W.K. Smith. 1996. Leaves and light capture: Light propagation and gradients of carbon fixation within leaves. Trends Plant Sci. 1:65-70.

Weaver, R.J. and R.M. Pool. 1971. Effect of ethephon and a morphactin on growth and fruiting of 'Thompson Seedless' and 'Carignane' grapes. Amer. J. Enol. Viticult. 22:234-239.

Weaver, R.J., A.J. Winkler, A. Leonard, and S.B. Mccune. 1961. Response of clusters of Vitis vinifera grapes to 2,4-D and related compounds. Hilgardia 31:113-125.

Weaver, R.J., A.J. Winkler, and S.B. Mccune. 1958. Some effects of 2,4-dichlorophenoxy acetic acid and related compounds on the grapevine. Amer. J. Enol. Viticult. 9:126-138.

Weintraub, R. 1953. 2,4-D mechanism of action. Agr. Food Chem. $1: 250-254$.

White, D.W.R. 2006. PEAPOD regulates lamina size and curvature in Arabidopsis. Proc. Natl. Acad. Sci. USA 103:13238-13243.

White, O.E. 1948. Fasciation. Bot. Rev. 14:319-358.

Wylie, R.B. 1939. Relationship between tissue organization and vein distribution in dicotyledon leaves. Amer. J. Bot. 26:219-225.

Zwieniecki, M.A., P.J. Melcher, C.K. Boyce, L. Sack, and N.M. Holbrook. 2002. Hydraulic architecture of leaf venation in Laurus nobilis L. Plant Cell Environ. 25:1445-1450. 